\title{
Recruiting individuals into the HTLV cohort study in the United Kingdom: clinical findings and challenges in the first six years, 2003 to 2009
}

L J Brant ${ }^{1,2}$, C Cawley 1,2, K L Davison (Katy.Davison@HPA.org.uk), ${ }^{1,2}$, G P Taylor3, the HTLV National Register Steering Group4

1. Health Protection Agency Centre for Infections, Immunisation Hepatitis and Blood Safety Department, London, United Kingdom

2. National Health Service Blood and Transplant, London, United Kingdom

3. Imperial College, Communicable Diseases, London, United Kingdom

4. The members of the group are listed at the end of the article

Brant LJ, Cawley C, Davison KL, Taylor GP, the HTLV National Register Steering Group. Recruiting individuals into the HTLV cohort study in the United Kingdom: clinical findings and challenges in the first six years, 2003 to 2009

Euro Surveill. 2011;16(46):pii=20017. Available online: http://www.eurosurveillance.org/ViewArticle.aspx?Articleld=20017

Human T-lymphotropic virus (HTLV) infection is rare in the United Kingdom (UK) and few studies are available worldwide. Following introduction of blood donation testing in 2002, a cohort of individuals could be identified and prospectively recruited to describe progression and onset of disease. Here we describe baseline characteristics of participants, and evaluate recruitment into the UK HTLV National Register over the first six years, from July 2003 to June 2009. A multicentre cohort study recruited participants from the UK blood services (recipients and donors) and specialist HTLV clinics. Almost half of the 148 participants recruited were blood donors, nine were blood transfusion recipients, 40 contacts and 29 clinic attendees (nine asymptomatic and 20 symptomatic). Most participants were HTLV-1 positive $(n=115) ; 11$ had HTLV-2 and 22 were HTLV-negative. Baseline self-completion questionnaires were received for $83 \%$. The most commonly reported condition was a past operation/serious illness (69\%). Twenty-six participants reported four or more possible signs/symptoms of HTLV-1associated myelopathy/tropical spastic paraparesis. Recruitment into a study of a rare, long-term infection is challenging. This cohort will enable descriptions of HTLV-associated disease progression amongst people recruited from varying sources; it is the first prospective study of its kind in Europe.

\section{Introduction}

Human T-lymphotropic viruses (HTLV) are enveloped, double-stranded RNA viruses. Type 1 (HTLV-1) was first described in 1980 [1] and type 2 (HTLV-2) in 1982 [2]. Most people infected with HTLV have a low ( $<5 \%$ risk of developing disease; however, there are relatively few studies on the natural history of HTLV infection worldwide and few prospective studies of HTLV-1-associated disease have taken place in Europe. Although evidence from epidemiological studies confirms the role of HTLV-1 in adult T-cell leukaemia/lymphoma (ATLL),
HTLV-associated myelopathy/tropical spastic paraparesis (HAM/TSP) and uveitis [3], more studies are needed to investigate the role of the virus in other disease outcomes, particularly other inflammatory disorders such as arthritis, urinary tract disorders and susceptibility to infectious diseases [4]. Long term follow-up studies could describe the timing and progression of disease from the asymptomatic carrier state to the known disease outcomes and investigate previously unsuspected disease associations.

HTLV-1 is endemic in southern Japan, the Caribbean, parts of Africa, the Middle East, South America and the Melanesian Islands of the south-west Pacific [3]. HTLV-2 is more commonly found among indigenous American populations and injecting drug users (IDU) [5]. Modes of transmission include transfusion of unscreened blood, mother-to-child contact (including breastfeeding), sex and injecting drug use [3]. HTLV is rare in the United Kingdom (UK); seroprevalence among blood donors and pregnant women is low (6 per million donations [6] and 340 per million women [7], respectively). In the 1980 s and 1990 s a large proportion of infections reported to UK HTLV national surveillance were among minority ethnic populations originating from HTLVendemic areas and consisted mainly of patients with HTLV-associated disease [8].

In Summer 2002, the UK blood services introduced blood donor testing for HTLV antibodies (anti-HTLV) [9]. It was recognised that some HTLV-positive donors may have made previous donation(s) before testing was introduced, so the blood services began a 'lookback' programme to trace the outcome and/or recipients of blood components derived from these donations, as they did when anti-HCV testing was introduced in the early 1990 [10]. These actions provided a rare opportunity to identify and prospectively recruit a cohort of individuals for long-term follow-up to investigate and 
describe clinical progression and onset of disease. All positive blood donors and recipients of their blood were offered the option to attend a specialist HTLV clinic. Their contacts, patients with symptomatic disease, and other people with HTLV were also seen at these clinics.

The HTLV National Register cohort study was established as a collaboration between National Health Service (NHS) Blood and Transplant (NHSBT), the Health Protection Agency (HPA) and Imperial College, London. The objectives were to describe the clinical state at diagnosis, determine the long-term outcome in HTLV-infected individuals and to investigate factors associated with transmission, disease and survival. Here we assess recruitment into the register in the first six years (July 2003 to June 2009) and describe the baseline health characteristics of the cohort.

\section{Methods \\ Participant consent, recruitment \\ and registration}

Consent and recruitment began in July 2003. All participants were asked to provide signed consent for up to four options: (i) processing and disclosure of personal data contained in medical records to the register co-ordinator, (ii) flagging the participant's NHS number in the NHS Health and Social Care Information Centre (NHSIC) (described below), (iii) approaching the participant's general practitioner (GP) for additional information if required and (iv) follow-up in order to be contacted for further information at a later date (including follow-up questionnaires). Consent to approach GPs was not included in the initial consent request to participants but introduced from September 2005 to maximise possibilities for follow-up of information about participants)

Participants were recruited prospectively and classified according to the source where they were first identified:

- Group A: HTLV-positive blood donors tested by the UK blood services,

- Group B: blood transfusion recipients identified through the UK blood services 'lookback' programme (HTLV-positive and -negative);

- Group C: contacts of HTLV-positive and -negative blood donors and recipients or symptomatic patients recruited through HTLV clinics (HTLVnegative contacts recruited from 2004);

- Group D: HTLV-positive symptomatic patients diagnosed with an HTLV-associated disease (from 2004);

- Group E: HTLV-positive asymptomatic clinic attendees who were not blood donors or linked to another study participant.

All HTLV-positive blood donors identified before July 2003 were invited to participate in writing in late
2003 by blood service clinicians and again when they attended a specialist HTLV clinic.

Recruitment of blood recipients identified through the HTLV 'lookback' was to enable the investigation of factors associated with onset of HTLV-related disease by providing a source of cases (infected recipients) and controls (uninfected recipients). Extrapolating from findings from the hepatitis C 'lookback' [11] indicated that for every 100 infected blood donors, 29 infected and 55 non-infected recipients would be identified. It was estimated that the first two years of testing would identify 120 infected blood donors, therefore 34 and 66 infected and non-infected recipients, respectively, might be identified. This would enable a formal statistical analysis at $80 \%$ power and $5 \%$ significance. However, by June 2009 the HTLV 'lookback' programme was almost complete and it was clear that the sample size would not be reached: the majority of transfusion recipients were not infected with HTLV [12] and few agreed to participate. Therefore recruitment of HTLVnegative individuals was halted by the steering group on ethical grounds.

At registration we collected details of name, address, date of birth, sex, General Practitioner (GP), the responsible clinician, recruitment source, date and result of HTLV test, HTLV type, risk exposure(s) and summary signs and symptoms of disease (if any). Age was calculated at date of consent.

At the time of publishing of this report, enrolment in the cohort is not complete and follow-up is currently open-ended.

\section{Baseline health status}

All participants were requested to complete a baseline self-completion health questionnaire (SCQ) in four parts. Section A collected the participant's demographic details (age, sex, marital status, number of children). Section B explored possible risk exposures, which were assigned, according to a hierarchy, as the participants' probable source of infection. The probable risk exposures, used by the HPA and NHSBT surveillance, were based upon published information about the epidemiology of HTLV and the opinion of HTLV experts. Information on general health and signs and symptoms of disease were gathered in sections $C$ (health in the past) and D (current health).

\section{Maintaining contact and assessing mortality outcomes}

Every patient registered with the NHS in the UK is identified by a unique NHS number. Researchers in the UK, whose studies have been granted ethical approval, can put a flag against a participant's NHS number, thereby identifying that person as a member of a particular study. For each flagged participant, the NHSIC notifies the register coordinator of movement between health authorities, cancer registration and/or death (including death certificate details). To maintain contact and 
participation, an annual newsletter was distributed to the participants, incorporating an address change form.

\section{Recruitment uptake}

Recruitment uptake was assessed for each recruitment group. Data on the number of transfusion recipients and HTLV-positive blood donors were obtained from NHSBT. Differences in characteristics of consenting and non-consenting blood donors were investigated using chi-squared test. Data on the number of HTLVpositive patients identified between July 2003 and June 2009 was obtained from the HPA [13]; information on symptoms (excluding blood donors, for whom uptake was known) were used to assess uptake in symptomatic and asymptomatic clinic attendees respectively; patients with unknown symptomatic/asymptomatic status were excluded $(n=152)$. Data on the number of contacts (HTLV-positive or negative) invited to participate at the specialist clinics were not available.

\section{Analysis of clinical data}

Data from Sections C and D of the baseline SCQ were tabulated using Stata version 10. Reported symptoms and health outcomes were reviewed by recruitment group. The following questions were considered to identify possible signs/symptoms of HAM/TSP: (i) can you walk unaided, (ii) do your legs feel weak, clumsy, jumpy or stiff, (iii) do you have pain in your lumbar spine/lower back, (iv) during the day, how often do you normally pass urine, (v) do you have to hurry to the toilet when you feel the need to pass urine, (vi) are you constipated? Two questions were considered together to possibly indicate Sjogren's syndrome: (i) are your eyes dry or itchy, and (ii) do you have a dry mouth?

\section{Ethical approval and data entry}

Ethical approval was obtained from the Northern and Yorkshire Multi-Centre Research Ethics Committee (03/03/021), with the HPA as the sponsoring body. Data were entered in duplicate into a secure MS Access database, and entries were validated before entry into the master database.

\section{Results}

Between July 2003 and June 2009, 148 people consented to participate in the study (Table 1). Most participants recruited in the first six months were blood donors (Figure) and most provided full consent as it was offered to them, although some declined consent for 'flagging', further follow-up and/or for GP contact (Table 1).

\section{Recruitment}

Group A: Blood donors

By June 2009, 146 HTLV-positive blood donors had been identified by NHSBT and other UK blood services. As of January $2010,48 \%$ had consented to participate (Table 1). Of the 76 non-consenting blood donors, 31 (41\%) were identified before recruitment started and were only invited to participate when (or if) they attended their clinical referral appointment and by letter. There was no difference between consenting and non-consenting blood donors with respect to sex (chi-squared=1.12, $p=0.291$ ), age group (chisquared=4.46, $p=0.486$ ), ethnicity (white or nonwhite, chi-squared $=0.07, p=0.786$ ), or donation year (chi-squared=6.48, $p=0.484$ ). The mean number of days between date of HTLV-positive donation and consent was 359 .

\section{Group B: Transfusion recipients}

Nine of the 109 living transfusion recipients tested as part of the HTLV 'lookback' programme [12] consented to participate, detailed data were not available on the other living transfusion recipients.

Group C: Contacts

The denominator for this group was not estimated.

Group D: Symptomatic patients

Between July 2003 and June 2009, 125 people known to have symptomatic HTLV infection (and who were not blood donors) were reported to the HPA (S. Ribeiro, personal communication, September 2010). Assuming that all were eligible, attended a specialist HTLV clinic and were invited to participate, $16 \%$ consented. Recruitment increased from $2.4 \%$ in the first year to $25 \%$ in the fifth year.

Group E: Asymptomatic clinic attendees

Forty-seven patients, known to be asymptomatic (and not blood donors) were reported to the HPA from July 2005 to June 2009 (S. Ribeiro, personal communication, September 2010). Assuming all were eligible and invited to participate, $19 \%$ were recruited.

\section{Demographics and characteristics}

The majority of participants were HTLV-1 positive (Table 1); of the HTLV-2 positive participants $82 \%$ were blood donors. Information on sex and date of birth was complete; three quarters were female. Blood transfusion recipients were the only group with more male than female participants. Blood donors were the youngest group recruited and symptomatic clinic attendees the eldest. The ethnic background of the groups differed: the majority of symptomatic patients were Black Caribbean whereas the majority of blood transfusion recipients were white.

All 20 symptomatic patients were recruited by clinicians from one single clinic. At registration, three participants had been diagnosed by clinicians with ATLL and eight with HAM/TSP; the remaining nine participants were reported to have gait problems, uveitis, generalised lymphadenopathy, chronic HTLV-1-driven lymphocytosis, neurological symptoms and mononeuritis multiplex.

Heterosexual sex (or heterosexual sex/mother-to-child transmission) was the main risk exposure reported (Table 1). Both the symptomatic and the asymptomatic 
clinic attendees that reported blood transfusion (in 1989 and 1985, respectively) as their risk exposure had not been identified during the blood services 'lookback', so transmission had not been confirmed.

Among the contacts, 16 people (seven with HTLV-1, one with HTLV-2, eight HTLV-negative) were current or previous sexual partners of HTLV-infected individuals, 10 (four with HTLV-1, six HTLV-negative) were children of positive parent(s), 10 (five with HTLV-1, one with HTLV-2, four HTLV-negative) were a family member of a positive individual, and two (both HTLV-positive) were mothers of positive individuals. One participant (HTLV-1-positive) was a close friend of a patient with

\section{TABLE 1}

Recruitment, consent and characteristics of participants by recruitment source, HTLV National Register, United Kingdom, July 2003-June $2009(\mathrm{n}=148)$

\begin{tabular}{|c|c|c|c|c|c|c|}
\hline & $\begin{array}{c}\text { Asymptomatic } \\
\text { clinic attendee } \\
\text { (Group E) }\end{array}$ & $\begin{array}{l}\text { Blood donor } \\
\text { (Group A) }\end{array}$ & $\begin{array}{l}\text { Blood recipient } \\
\text { (Group B) }\end{array}$ & $\begin{array}{l}\text { Contact } \\
\text { (Group C) }\end{array}$ & $\begin{array}{c}\text { Symptomatic } \\
\text { patient } \\
\text { (Group D) }\end{array}$ & Total \\
\hline Number eligible & 47 & 146 & 109 & $\mathrm{n} / \mathrm{a}$ & 123 & 425 \\
\hline Number recruited (\%) & 9 (19) & $70(48)$ & $9(8)$ & $40(n / a)$ & $20(16)$ & $148(35)^{a}$ \\
\hline Proportion of cohort in \% & 6.1 & 47.3 & 6.1 & 27.0 & 13.5 & 100 \\
\hline \multicolumn{7}{|l|}{ Consent } \\
\hline Full - three options & 1 & 42 & 8 & 20 & 7 & 78 \\
\hline Full $^{\mathrm{b}}$ - four options & 7 & 16 & 0 & 13 & 10 & 46 \\
\hline Partial & 1 & 12 & 1 & 7 & 3 & 24 \\
\hline Declined flagging ${ }^{c, d}$ & 0 & 7 & 1 & 2 & 2 & 12 \\
\hline Declined further contact ${ }^{d}$ & 0 & 4 & 0 & 1 & 2 & 7 \\
\hline Refused GP consent $t^{d, e}$ & 1 & 4 & 0 & 4 & 0 & 9 \\
\hline Baseline SCQ returned & 6 & 62 & 8 & 33 & 14 & $123(83.1)$ \\
\hline \multicolumn{7}{|l|}{ Characteristics } \\
\hline Number of females ${ }^{f}$ & 6 & 58 & 3 & 28 & 16 & $111(75.0)$ \\
\hline Mean age (range) & $56.3(21.8-81.4)$ & $45.3(17.6-70.5)$ & $56.2(33.3-76.2)$ & $47.9(3.6-79.3)$ & $56.8(34.9-85.5)$ & $48.9(3.6-85.5)$ \\
\hline \multicolumn{7}{|l|}{ Ethnicity } \\
\hline White & 1 & 32 & 8 & 10 & 2 & $53(35.8)$ \\
\hline Black Caribbean & 7 & 27 & 0 & 24 & 16 & $74(50.0)$ \\
\hline Other $^{g}$ & 1 & 11 & 1 & 6 & 2 & $21(14.2)$ \\
\hline \multicolumn{7}{|l|}{ HTLV type } \\
\hline HTLV-1 & 9 & 61 & 5 & 20 & 20 & $115(77.7)$ \\
\hline HTLV-2 & 0 & 9 & 0 & 2 & 0 & $11(17.4)$ \\
\hline HTLV-negative & 0 & 0 & 4 & 18 & 0 & 22 (14.9) \\
\hline \multicolumn{7}{|l|}{ Risk exposure(s) } \\
\hline Heterosexual sex & 0 & 26 & 0 & 12 & 1 & $39(26.4)$ \\
\hline Mother to child & 4 & 9 & 0 & 15 & 5 & $33(22.3)$ \\
\hline Heterosexual sex and mother to child & 4 & 18 & 0 & 11 & 12 & $45(30.4)$ \\
\hline Blood transfusion & 1 & 7 & 9 & 0 & 1 & $18(12.2)$ \\
\hline Blood transfusion and mother to child & 0 & 1 & 0 & 0 & 0 & $1(0.7)$ \\
\hline Not known & 0 & 9 & 0 & 2 & 1 & $12(8.1)$ \\
\hline
\end{tabular}

GP: general practitioner; HTLV: human T-lymphotropic virus; NHSIC: National Health Service Health and Social Care Information Centre; SCQ: self-completion questionnaire.

a Excluding contacts, because a denominator was not available.

b Full consent is as it was offered to the patient. The fourth option (consent to contact the patient's GP for additional information) was added in September 2005.

c Flagging refers to putting a flag against a participant's NHS number. For each flagged participant, the NHSIC notifies the register coordinator of movement between health authorities, cancer registration and/or death (including death certificate details).

d Patients can be shown more than once in the declined section as they could have declined one or more options.

e A further three patients gave consent but did not explicitly specify which parts they consented to; they are included in the total of 24 but not in the breakdown.

Reporting of sex was $100 \%$ complete.

g Other ethnicities reported were: asymptomatic (1 Black African), blood donor (2 Black African, 2 Black Other, 1 Indian, 1 Pakistani, 4 Asian other, 1 Other -no further details), Blood recipient (1 Bangladeshi), Contacts (2 Black Other, 1 Asian Other, 3 Other-no further details), Symptomatic (1 Chinese, 1 Other). 
ATLL, and for one (HTLV-1-positive) no relationship was stated.

\section{Baseline health status}

Baseline SCQs were received for most participants; the response rate was highest among blood transfusion

\section{FIGURE}

Consent into the HTLV National Register by 12-month period and recruitment source, United Kingdom, July 2003-June 2009, $(\mathrm{n}=148)$

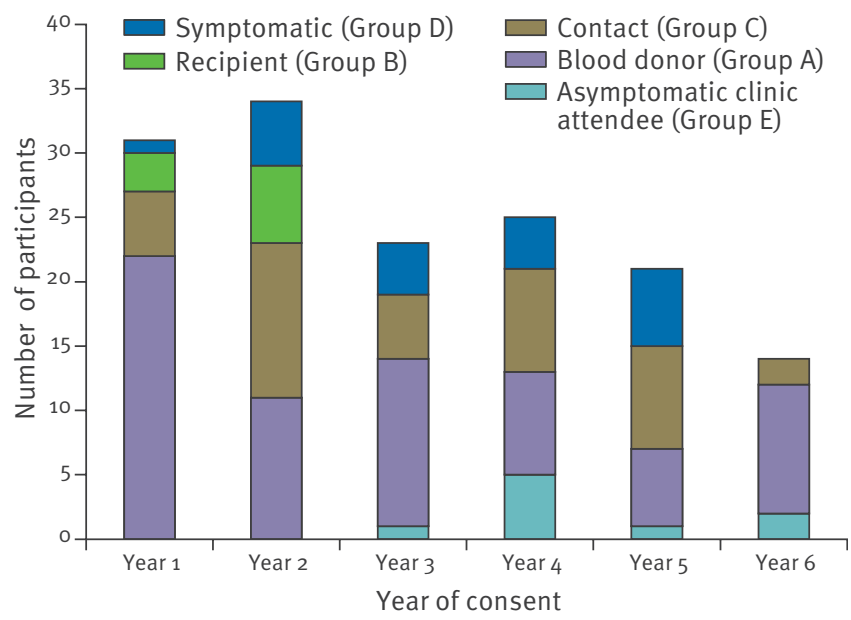

HTLV: human T-lymphotropic virus. recipients and donors (Table 1). At least $90 \%$ of respondents answered each question. The few questions that were more poorly completed required more than one response e.g. do you have any problems with your nails, scalp, skin (tick yes/no to each). Here, $12-33 \%$ of respondents left one or more response blank.

Overall, past surgery or serious illness was the clinical feature most commonly reported by participants, followed by any treatment for back pain (physiotherapy/ medication) and cystitis or kidney infection treated with antibiotics (Table 2). Half of the symptomatic patients reported arthritis. Forty-four percent of reports of a past operation or serious illness related to obstetric or gynaecological problems (e.g. hysterectomy, caesarean section, ectopic pregnancy) or routine procedures (e.g. appendectomy, tonsillitis).

A greater proportion of symptomatic patients reported four or more possible signs/symptoms of HAM/TSP than other groups (Table 2). Seven blood donors (11\%) reported four or more possible sign/symptoms of HAM/TSP (one had a formal diagnosis of HAM/TSP at registration at the clinic) and more than three-quarters of blood donors reported between one and three symptoms.

Ten participants reported symptoms indicative of Sjogren's syndrome (Table 3). Few of the 123

TABLE 2

Number and proportion of participants having ever experienced various health outcomes as reported on the baseline selfcompletion health questionnaire, by recruitment type, United Kingdom, July 2003-June 2009 ( $\mathrm{n}=123$ )

\begin{tabular}{|c|c|c|c|c|c|c|c|c|}
\hline & $\begin{array}{c}\text { Asymptomatic } \\
\text { clinic } \\
\text { attendee } \\
\text { (Group E) }\end{array}$ & $\begin{array}{c}\text { Blood } \\
\text { donor } \\
(\text { Group A) }\end{array}$ & $\begin{array}{l}\text { Blood } \\
\text { recipient } \\
\text { HTLV-positive } \\
\text { (Group B) }\end{array}$ & $\begin{array}{c}\text { Blood } \\
\text { recipient } \\
\text { HTLV-negative } \\
\text { (Group B) } \\
\end{array}$ & $\begin{array}{l}\text { Contact } \\
\text { HTLV-positive } \\
\text { (Group C) }\end{array}$ & $\begin{array}{l}\text { Contact } \\
\text { HTLV-negative } \\
\text { (Group C) }\end{array}$ & $\begin{array}{l}\text { Symptomatic } \\
\text { patient } \\
\text { (Group D) }\end{array}$ & Total \\
\hline $\begin{array}{l}\text { Number returning } \\
\text { questionnaire }\end{array}$ & 6 & 62 & 4 & 4 & 18 & 15 & 14 & 123 \\
\hline $\begin{array}{l}\text { Operation or serious } \\
\text { illness }\end{array}$ & 6 & 41 & 4 & 4 & 13 & 7 & 10 & $85(69.1)$ \\
\hline $\begin{array}{l}\text { Uveitis, tuberculosis, } \\
\text { thrombosis or thyroid } \\
\text { disease }\end{array}$ & 2 & 11 & 1 & 0 & 3 & 2 & 5 & $24(19.5)$ \\
\hline $\begin{array}{l}\text { Cystitis or kidney infection } \\
\text { treated with antibiotics }\end{array}$ & 1 & 18 & 0 & 0 & 10 & 5 & 5 & $39(31.7)$ \\
\hline Arthritis & 3 & 14 & 1 & 0 & 6 & 2 & 7 & $33(26.8)$ \\
\hline $\begin{array}{l}\text { Enlarged glands, hepatitis, } \\
\text { jaundice or gallstones }\end{array}$ & 2 & 18 & 2 & 0 & 3 & 2 & 5 & $32(26.0)$ \\
\hline $\begin{array}{l}\text { Attended a doctor because } \\
\text { of shortness of breath }\end{array}$ & 2 & 17 & 2 & 2 & 5 & 5 & 2 & $35(28.5)$ \\
\hline $\begin{array}{l}\text { Attended a doctor because } \\
\text { of difficulty passing urine, } \\
\text { constipation or impotence }\end{array}$ & 3 & 7 & 2 & 2 & & 3 & 7 & $25(20.3)$ \\
\hline $\begin{array}{l}\text { Had treatment } \\
\text { (physiotherapy/medication) } \\
\text { for back pain }\end{array}$ & 1 & 22 & 1 & 1 & 2 & 6 & 9 & $42(34.2)$ \\
\hline Attended a dermatologist & 0 & 12 & 0 & 1 & 3 & 4 & 4 & $24(19.5)$ \\
\hline Had cold sores & 1 & 16 & 1 & 2 & 4 & 0 & 1 & $25(20.3)$ \\
\hline Any of these? & 6 & 54 & 4 & 5 & 18 & 11 & 14 & $112(90.2)$ \\
\hline
\end{tabular}

HTLV: human T-lymphotropic virus 
participants reported having ever had tuberculosis, uveitis or thyroid disease (one, eight and nine, respectively).

\section{Flagging, mortality and cancer}

In total 133 (90\%) participants consented to flagging; 132 (99\%) were successfully flagged, one could not be traced by NHSIC. Of the remaining 15 participants, all but one (an HTLV-negative transfusion recipient) were attending specialist HTLV clinic(s).

Death notifications were received for five participants; two transfusion recipients (both heart disease-related) and three symptomatic patients (incident ATLL, relapsed ATLL and alcohol toxicity). Eleven cancer registration notifications were received for nine participants: one blood donor (HTLV-1: malignant neoplasm of breast), two HTLV-negative contacts (one with malignant neoplasm of bladder, prostate and colon; the other with carcinoma in situ of cervix uteri), two HTLV-1 positive blood transfusion recipients (malignant neoplasm of prostate, and melanoma in unspecified parts of face), and four HTLV-1-positive symptomatic patients (acute myelogenous leukaemia, acute lymphoblastic leukaemia, melanoma in situ of ear and external auricular canal, and neoplasm of uncertain or unknown behaviour).

\section{Discussion}

The introduction of HTLV blood donation testing in 2002 meant that asymptomatic carriers, a group previously under-diagnosed and under-reported to routine surveillance [8], could be prospectively identified, recruited and followed up. This is the first prospective cohort study of its kind in Europe. The flexibility of study recruitment has enabled inclusion of other patient groups and contacts to allow descriptions and comparisons of morbidity, mortality and disease progression. These data show that a large proportion of the cohort have a number of sign/symptoms which, when taken together, could indicate HAM/TSP.

HTLV-1 is more frequently detected than HTLV-2 in the UK $[8,14]$ and few study participants had HTLV-2. European blood donors found to be infected with HTLV had generally, where typable, HTLV-1 [15].This is in contrast to a blood donor study in the United States, where $72 \%$ had HTLV-2 [16] and $24 \%$ reported IDU risk exposure; no participants in our cohort reported to being IDU. Other studies have shown an association between HTLV-2 and IDU $[16,17]$; it is possible that more detailed questioning of HTLV-2-infected participants might reveal previously undisclosed risks of IDU.

HTLV in the UK is more common among individuals born in endemic areas $[13,18,19]$ or among children born to parents from endemic areas [20], such as the Caribbean $[3,4]$. Therefore it was unsurprising that a large proportion of register participants were of Black Caribbean ethnicity. Among blood donors in the study, a disproportionate number were non-White; only $5 \%$ of the blood donor population is non-White (S Lattimore, personal communication, October 2011). The main risk exposures were mother-to-child transmission and heterosexual sex; many people reported both exposures. This probably reflects the epidemiology of HTLV infection in the UK, and that many of the study participants were born to parents from endemic areas and

TABLE 3

Number of study participants with possible signs/symptoms of HAM/TSP and Sjorgen's syndrome as reported on the baseline self-completion health questionnaire, by recruitment type, United Kingdom, July 2003-June 2009 (n=123)

\begin{tabular}{|c|c|c|c|c|c|c|c|c|}
\hline & $\begin{array}{c}\text { Asymptomatic } \\
\text { clinic attendee } \\
\text { (Group E) }\end{array}$ & $\begin{array}{l}\text { Blood donor } \\
\text { (Group A) }\end{array}$ & $\begin{array}{l}\text { Blood recipient } \\
\text { HTLV-positive } \\
\text { (Group B) }\end{array}$ & $\begin{array}{c}\text { Blood recipient } \\
\text { HTLV-negative } \\
\text { (Group B) }\end{array}$ & $\begin{array}{c}\text { Contact } \\
\text { HTLV- positive } \\
\text { (Group C) }\end{array}$ & $\begin{array}{c}\text { Contact } \\
\text { HTLV-negative } \\
\text { (Group C) }\end{array}$ & $\begin{array}{c}\text { Symptomatic } \\
\text { patient } \\
\text { (Group D) }\end{array}$ & Total \\
\hline \multicolumn{9}{|c|}{ Total number of participants with SCQ and in brackets percentage reported as asymptomatic for HTLV on the registration forma } \\
\hline & $6(100.0)$ & $62(80.7)$ & $4(50.0)$ & $4(n / a)$ & $18(83.3)$ & $15(\mathrm{n} / \mathrm{a})$ & $14(0)$ & $123(59)$ \\
\hline \multicolumn{9}{|c|}{ Number of possible signs/symptoms of HAM/TSPb reported by the participants } \\
\hline o & 3 & 9 & 0 & o & 3 & 2 & 0 & 17 \\
\hline 1 & 1 & 23 & 1 & 2 & 8 & 9 & 1 & 45 \\
\hline 2 & 0 & 13 & 1 & 1 & 1 & 1 & 2 & 19 \\
\hline 3 & 0 & 8 & 1 & 1 & 3 & 1 & 0 & 14 \\
\hline 4 & 0 & 4 & 0 & 0 & 2 & 2 & 4 & 12 \\
\hline 5 & 0 & 1 & 0 & 0 & 1 & 0 & 1 & 3 \\
\hline$>5$ & 2 & 2 & 1 & 0 & 0 & 0 & 6 & 11 \\
\hline \multicolumn{9}{|c|}{ Reported symptoms indicative of Sjogren's syndrome ${ }^{c}$} \\
\hline & 1 & 4 & 0 & 0 & 2 & 1 & 2 & 10 \\
\hline
\end{tabular}

HAM: HTLV-associated myelopathy; HTLV: human T-lymphotropic virus; SCQ: self-completion questionnaire; TSP: tropical spastic paraparesis.

a Not reported whether asymptomatic/symptomatic on registration form for six blood donors, one HTLV-positive recipient and one HTLVpositive contact.

b Possible signs/symptoms of HAM/TSP include: (i) being unable to walk unaided, (ii) legs which feel weak, clumsy, jumpy or stiff, (iii) pain in the lumbar spine/lower back, (iv) passing urine more than five times per day, (v) having to hurry to the toilet to pass urine, (vi) constipation. Possible symptoms of Sjogren's syndrome included here are dry or itchy eyes and dry mouth. 
probably acquired their infection abroad. Many participants therefore may have long-standing infections; interpretation of health data will need to take this into account. The excess of female participants has also been reported previously in other UK-based research studies [14 20] and surveillance data [8] and elsewhere $[16,21-23]$, so was expected.

Estimates suggest that 20-30,000 people have HTLV infection in the UK [14], most are undiagnosed. Blood donors are currently the only population group undergoing regular testing; therefore they are an important source of participants, despite the decline in the number of HTLV-infected donors [9]. Specialist HTLV clinics will become increasingly important in identifying and recruiting other asymptomatic people, through testing of relatives and contacts of positive individuals.

Ever having had cystitis or kidney infection treated with antibiotics was one of the most commonly reported conditions; this was also reported amongst US blood donors [24], although the association in the multivariable models only remained statistically significant in HTLV-2-infected subjects. A range of autoimmune disorders have been associated with HTLV, including polymyositis [25] and arthritis [24]. In our study, a relatively large number of participants reported having had arthritis, although without a suitable control group, it is not possible to say whether this was associated with HTLV infection or not. A number of studies have also found associations between HTLV and uveitis [3], tuberculosis [26] and thyroiditis [27], but few HTLV National Register participants reported these conditions.

Blood donor recruitment was higher during prospective recruitment, which suggests that active recruitment of blood donors during their post-test discussion with blood service staff presents the best opportunity to discuss participation and obtain consent.

A combination of signs and symptoms was used as possible indicators of HAM/TSP. All participants who had been formally diagnosed with HAM/TSP and had returned a baseline SCQ reported four or more signs or symptoms. However, so too did two HTLV-negative contacts and four blood donors, which could suggest that the signs and symptoms used in this study were useful, but not very specific. Whilst each symptom alone does not constitute a significant risk, the constellation of four to five symptoms points towards HAM/TSP. The high level of consent for flagging, as well as regular newsletters, will minimise loss to follow-up and ensure that health, mortality and cancer data will be near complete, and final outcome determined. Combined with follow-up health data, requested every two years, this will provide information on whether these individuals have subclinical disease that will become more manifest.

Recruitment into the register varied by group, being proportionally to its larger size higher for blood donors, the largest group, than for the other recruitment groups, although it was lower than expected. By using routine surveillance data it was estimated that recruitment of symptomatic and asymptomatic individuals of Groups D and E was low, although improved over time. However as many newly diagnosed patients would only be invited to participate on their second or subsequent annual visit to the clinic and only one specialist centre recruited participants until 2008, the proportion of recruited patients is likely to be an underestimate.

From the outset, the planned control group for formal statistical analysis were uninfected blood recipients identified through the HTLV 'lookback' [11]. Unfortunately the sample size was not reached: the majority of transfusion recipients were not infected with HTLV [12] and few agreed to participate. Patients receiving transfusions are often elderly and/or very ill [11], so participating in a study that may be perceived as having little direct benefit may not be their first priority. The HTLV register echoes findings from other cohort studies $[28,29]$, that finding consenting participants for long-term research studies is challenging. Negative contacts could be an alternative control group, but recruitment of these was also low. Therefore recruitment of HTLV-negative individuals was halted by the steering group on ethical grounds. Alternative methods of obtaining data on negative controls need to be identified, including the use of population-level data or recruiting negative blood donors as an alternative; the latter would involve additional ethical approval.

Recruitment into a study of a rare, long-term infection such as HTLV has been challenging. However, follow up of a cohort such as this will enable descriptions of HTLV-associated disease progression to be made amongst people recruited from varying sources. The UK HTLV National Register is the first prospective study of its kind in Europe.

\section{Acknowledgments}

We would like to thank the patients for enrolling and participating in the study, NHSBT clinicians for recruiting blood donors and the clinicians and nurses working in specialist HTLV clinics for recruiting patients into the study. We would also like to thank Shirley Cole, Keith Eldridge, Fariba Kirwan and Alan Sheridan for their administrative support.

Steering group members:

Lisa Brant (Health Protection Agency and NHS Blood and Transplant); Su Brailsford (NHS Blood and Transplant and Health Protection Agency); Sally Brearley, Caoimhe Cawley (Health Protection Agency and NHS Blood and Transplant); Katy Davison (Health Protection Agency and NHS Blood and Transplant); Alexandra Fedina(Imperial College Healthcare NHS Trust); Helen Harris (Health Protection Agency); Patricia Hewitt, (NHS Blood and Transplant); Meaghan Kall (Health Protection Agency); Mary Ramsay (Health Protection Agency); Sonia Ribeiro (Health Protection Agency); Graham Taylor (Imperial College Imperial College Healthcare NHS Trust); Jennifer Tosswill (Health Protection Agency). 


\section{References}

1. Poiesz BJ, Ruscetti FW, Gazdar AF, Bunn PA, Minna JD, Gallo $R C$. Detection and isolation of type $C$ retrovirus particles from fresh and cultured lymphocytes of a patient with cutaneous T-cell lymphoma. Proc.Natl.Acad.Sci.U.S.A. 1980;77(12):7415-9.

2. Kalyanaraman VS, Sarngadharan MG, Robert-Guroff $M$, Miyoshi I, Golde D, Gallo RC. A new subtype of human T-cell leukemia virus (HTLV-2) associated with a T-cell variant of hairy cell leukemia. Science. 1982;218(4572):571-3.

3. Manns A, Hisada M, La Grenade L. Human T-lymphotropic virus type I infection. Lancet. 1999;353(9168):1951-8.

4. Proietti FA, Carneiro-Proietti AB, Catalan-Soares BC, Murphy EL. Global epidemiology of HTLV-I infection and associated diseases. Oncogene. 2005;24(39):6058-68.

5. Murphy EL, Mahieux R, de The G, Tekaia F, Ameti D, Horton J, et al. Molecular epidemiology of HTLV-2 among United States blood donors and intravenous drug users: an age-cohort effect for HTLV-2 RFLP type aO. Virology. 1998;242(2):425-34.

6. Taylor GP, Bodeus M, Courtois F, Pauli G, Del Mistro A, Machuca A, et al. The seroepidemiology of human T-lymphotropic viruses: types I and II in Europe: a prospective study of pregnant women. J Acquir.Immune Defic.Syndr. 2005;38(1):104-9

7. Payne LJ, Tosswill JH, Taylor GP, Zuckerman M, Simms I. In the shadow of HIV-HTLV infection in England and Wales, 19872001. Commun Dis Public Health 2004;7(3):200-6.

8. Davison KL, Dow B, Barbara JA, Hewitt PE, Eglin R. The introduction of anti-HTLV testing of blood donations and the risk of transfusion-transmitted HTLV, UK: $2002-2006$. Transfus.Med. 2009;19(1):24-34.

9. Dougan S, Smith A, Tosswill J, Davison K, Zuckerman M, Taylor G. New diagnoses of HTLV infection in England and Wales: 2002-2004. Euro Surveill. 2005;10(10): pii=569. Available from: http://www.eurosurveillance.org/ViewArticle. aspx?Articleld $=569$

10. Hewitt PE, Howell DR, Brant LJ, Taylor GP. HTLV lookback in NHS Blood and Transplant reveals the efficacy of leucodepletion. Abstracts of the XXXIst International Congress of the International Society of Blood Transfusion in joint cooperation with the 43 rd Congress of the DGTI, Berlin, Germany, 26 Jun-1 Jul 2010. P-0620. Vox Sang. 2010;99(Suppl 1): 320-1. 2010.

11. Tosswill JH, Taylor GP, Tedder RS, Mortimer PP. HTLV-I/II associated disease in England and Wales, 1993-7: retrospective review of serology requests. BMJ 2000;320(7235):611-2.

12. Orland JR, Engstrom J, Fridey J, Sacher RA, Smith JW, Nass C, et al. Prevalence and clinical features of HTLV neurologic disease in the HTLV Outcomes Study. Neurology. 2003;61(11):1588-94.

13. Machuca A, Tuset C, Soriano V, Caballero E, Aguilera A, Ortiz Ortiz de Lejarazu R. Prevalence of HTLV infection in pregnant women in Spain. Sex Transm.Infect. 2000;76(5):366-70.

14. Ades AE, Parker S, Walker J, Edginton M, Taylor GP, Weber JN. Human T cell leukaemia/lymphoma virus infection in pregnant women in the United Kingdom: population study. BMJ. 2000;320(7248):1497-501.

15. Cooke FJ, Geretti AM, Zuckerman M. Human T-cell lymphotropic virus antibody prevalence in HIV-1-infected individuals attending a sexual health clinic in South-East London. J.Med. Virol. 2005;76(2):143-5.

16. Turner CG, Cohen CE, Sabin CA, Tosswill JH, Best JM, Taylor GP, et al. The seroepidemiology of HTLV-I amongst genitourinary medicine (GUM) attendees in South East London. J.Clin.Virol. 2008;43(2):253-4.

17. Murphy EL, Glynn SA, Fridey J, Smith JW, Sacher RA, Nass $C C$, et al. Increased incidence of infectious diseases during prospective follow-up of human T-lymphotropic virus type IIand I-infected blood donors. Retrovirus Epidemiology Donor Study. Arch Intern Med. 1999;159(13):1485-91. Arch Intern Med. 1999 Jul 12;159(13):1485-91.

18. Silva MT, Harab RC, Leite AC, Schor D, Araujo A, Andrada-Serpa MJ. Human T lymphotropic virus type 1 (HTLV-1) proviral load in asymptomatic carriers, HTLV-1-associated myelopathy/ tropical spastic paraparesis, and other neurological abnormalities associated with HTLV-1 infection. Clin Infect Dis. 2007;44(5):689-92.

19. Hisada M, Stuver SO, Okayama A, Li HC, Sawada T, Hanchard $B$, et al. Persistent paradox of natural history of human $T$ lymphotropic virus type I: parallel analyses of Japanese and Jamaican carriers. J.Infect.Dis. 2004;190(9):1605-9.

20. Murphy EL, Glynn SA, Fridey J, Sacher RA, Smith JW, Wright DJ, et al. Increased prevalence of infectious diseases and other adverse outcomes in human T lymphotropic virus types I- and II-infected blood donors. Retrovirus Epidemiology Donor Study (REDS) Study Group. J.Infect.Dis. 1997;176(6):1468-75.
21. Morgan OS, Rodgers-Johnson P, Mora C, Char G. HTLV-1 and polymyositis in Jamaica. Lancet. 1989;2(8673):1184-7.

22. Matsuzaki T, Otose H, Hashimoto K, Shibata Y, Arimura $\mathrm{K}$, Osame $\mathrm{M}$. Diseases among men living in human T-lymphotropic virus type I endemic areas in Japan. Intern. Med. 1993;32(8):623-8.

23. Kawai H, Inui T, Kashiwagi S, Tsuchihashi T, Masuda K, Kondo A, et al. HTLV-I infection in patients with autoimmune thyroiditis (Hashimoto's thyroiditis). J.Med.Virol. 1992;38(2):138-41.

24. Soldan K, Ramsay M, Robinson A, Harris H, Anderson N, Caffrey $\mathrm{E}$, et al. The contribution of transfusion to HCV infection in England. Epidemiol Infect 2002;129(3):587-91.

25. Iversen A, Liddell K, Fear N, Hotopf M, Wessely S. Consent, confidentiality, and the Data Protection Act. BMJ. 2006;332(7534):165-9.

26. Al Shahi R, Vousden C, Warlow C; Scottish Intracranial Vascular Malformation Study (SIVMS) Steering Committee. Bias from requiring explicit consent from all participants in observational research: prospective, population based study. BMJ. 2005;331(7522):942. 